\title{
LA BÚSQUEDA ESPIRITUAL A TRAVÉS DEL TURISMO. SU ARTICULACIÓN DESDE EL LADO DE LA OFERTA
}

\author{
María Albert Rodrigo \\ Universitat de Valencia \\ https://orcid.org/0000-0001-6371-2556
}

\section{RESUMEN}

Desde mediados del siglo pasado hemos asistido a una ampliación de las posibilidades turísticas de forma creciente; han aparecido nuevos tipos o han diversificado su oferta (histórico, cultural, ambiental, étnico, etc.), ampliando así su campo de acción. Queremos pues, reflexionar sobre un nuevo tipo de turismo que se refiere a la circulación mundial de personas que en sus desplazamientos recorren las redes espirituales en busca de nuevas experiencias de lo sagrado y de la vivencia espiritual. Nos hemos acercado a este proceso de reencantamiento del mundo a partir de los centros de terapias holísticos que son en gran medida los nodos que articulan esta nueva espiritualidad transversal que se mueve por los circuitos que conectan culturas indígenas con redes globales y que está generando unas nuevas coordenadas de lo que puede entenderse por religioso.

Palabras clave: turismo espiritual; turismo étnico; turismo cultural; nuevas espiritualidades; new age.

\section{Spiritual Search Through Tourism.Your Articulation from the Side of the Offer}

\section{ABSTRACT}

From mid twentieth century we have assisted to a widening in ever-growing tourist possibilities; new ways of travelling have appeared or have diversified their offers (including historical, cultural, environmental, ethnic, etc.) widening thus their action field. We would

Fecha de recepción: 29 de junio de 2018.

Fecha de aceptación: 14 de marzo de 2019.

* Departamento de Sociología y Antropología Social. Facultad de Ciencias Sociales. Universitat de Valencia. Campus de Tarongers. 46021 VALENCIA (España).E-mail: maria.albert@uv.es 
like to pay attention to a new tourist trend, referred to those who travel around the nets New Age, searching new sacred experiences and spiritual living. We have approached this new process of re-enchantment of the world from the alternative, holistic therapy centers, and all of this kind, which are up to a certain level the links that join this new holistic, transversal and personal spirituality that goes around the places that connect indigenous cultures with global nets, which is creating new coordinates that can be understood as religious.

Keywords: spiritual tourism; ethnic tourism; cultural tourism; new spiritualities; new age.

\section{INTRODUCCIÓN: NUEVAS FORMAS ESPIRITUALES}

Desde finales del siglo pasado venimos observando, cada vez con mayor claridad, el desarrollo de "nuevas" formas espirituales como una continuidad del movimiento new age y de sus antecedentes en los movimientos contracultura y hippies de los años cincuenta y sesenta. La literatura especializada se ha referido a las nuevas manifestaciones del fenómeno religioso como religiones no teístas (Díaz-Salazar 1994); constelación místicoesotérica (Champion, 1995); Nuevos movimientos espirituales y culturales (Shimazono, 1999); Nuevos Movimientos Religiosos (Hervieu-Leger, 2005); Corriente Secular de Religiosidad Alternativa (Lenoir, 2005) y un largo etc. que funciona mediante consumos selectivos conformando religiosidades a la carta, con un número creciente de seguidores a través de revistas, cursos, talleres, retiros, formaciones, etc. en una organización flexible y cambiante (Champion, 1995; Mardones, 1999; Davie, 2011). Así, en la experiencia cotidiana de sus seguidores se ha producido una transformación desde la religión hacia lo religioso, sagrado o espiritual (Albert y Hernández, 2014a), desde lo colectivo e institucionalizado hacia lo individual y experiencial.

Cada vez es más frecuente practicar yoga o taichí, ir a clases de biodanza, incluso acercarse a un centro budista para aprender a meditar, asistir a talleres de mindfulness o a la infinidad de actividades que en esta línea se ofrecen en las, cada vez más numerosas, salas polivalentes, polideportivos, escuelas de adultos, centros culturales, así como en centros o escuelas especializados conocidos como de Terapias Alternativas, Holísticos, Integrales, Tiendas de Productos Alternativos, Centros de Espiritualidad Oriental, Centros de Terapias Psicológicas no reconocidas por la academia, Centros Esotéricos y espacios neochamánicos presentes en los centros urbanos principalmente. En los últimos años, como una posibilidad más de esta variada oferta, ha proliferado el viaje espiritual o místico que emprenden algunas personas en su búsqueda de respuestas, de bienestar, de autoconocimiento y de crecimiento personal. Como apunta, Lanfant (1994) lo lúdico forma parte de la vida diaria, en parte porque se asiste a una "turistificación" de las sociedades.

En muchos casos se trata de viajes de largo recorrido hacia tierras lejanas en los que, con grandes dosis de exotismo, se contacta con una cultura distinta. Pero lo que nos resulta más claramente destacable es que, en paralelo, se busca realizar un viaje interior, espiritual, 
a veces incluso iniciático y que se concreta en experiencias sensoriales exóticas, que se viven individualmente y que se comparten con el grupo con el que se viaja.

La investigación ${ }^{1}$ en la que se enmarca este artículo nos ha permitido profundizar en los desarrollos de estas "nuevas" formas espirituales. Y, específicamente, en este artículo nos hemos centrado en cómo se está configurando y articulando este nuevo tipo de turismo espiritual. Nos hemos acercado a este fenómeno a partir de una metodología basada en la combinación de entrevistas en profundidad y observaciones realizadas durante los años 2016 y 2017 tanto en espacios de encuentro (Ferias, Festivales, Congresos, Jornadas, etc.) como a los responsables o personas vinculadas a centros/escuelas de terapias, holísticos, integrales, alternativos, etc. que articulan el movimiento de personas que genera esta búsqueda espiritual. El ámbito de investigación se ha situado en la Comunidad Valenciana, tomando la ciudad de Valencia como eje central de nuestro trabajo de campo, aunque entendemos que puede hacerse extensivo al conjunto de la geografía española, en tanto en cuanto vamos a encontrarnos con una oferta semejante. En concreto, en el trabajo que aquí se presenta se han utilizado las notas de campo de las observaciones y siete de las entrevistas realizadas durante la investigación marco.

Cabe señalar, algunas de las características de la ciudad de Valencia, considerada una ciudad global mediana ${ }^{2}$. En línea con las tendencias globales, incorpora la aparición y la extensión de los movimientos psico-físico-espirituales visibles en la amplia y nutrida oferta de centros de terapias holísticas, tiendas de productos alternativos, así como en centros de espiritualidad oriental (Albert y Hernández, 2014b). La articulación de dichos movimientos se produce fundamentalmente a través de los centros y escuelas mencionados, así como en lugares de encuentro de diverso calado, algunos con nombre propio como Biocultura y Festiva que se celebran periódicamente en la ciudad. Estos, son pues los espacios a través de los cuales nos hemos acercado a sus protagonistas, buscadores espirituales que actualmente dirigen o gestionan estos nodos que articulan las redes espirituales que han alcanzado un ámbito global. En lo que sigue, se pretende pues, ver cuáles son las características y cómo se articulan fuera de los cauces acostumbrados y normalizados estos viajes espirituales.

La proliferación de este tipo de viajes, son una muestra más de cómo nos hallamos inmersos en un proceso de reencantamiento del mundo, entendido éste como la emergencia global de una nueva espiritualidad holística, transversal y personal que está generando unas nuevas coordenadas de lo que puede entenderse por religioso. De acuerdo con Ritzer (2000) en este reencantamiento del mundo, el turismo juega y está llamado a jugar un papel decisivo. Veremos pues, en primer lugar, desde una elaboración teórica y conceptual los diferentes tipos de turismos alrededor del que gira este turismo espiritual. En segundo lugar, describimos a sus principales protagonistas, así como sus motivaciones principales para ofertar este tipo de viajes, tratamos pues, de responder a la pregunta: ¿quiénes son? En

1 Proyecto de I+D titulado "Turismo étnico y rituales New Age en los Altos de Chiapas, México (GV/2015/038), dirigido por la Dra. M Eugenia Bayona Escat y financiado por la Generalitat Valenciana.

2 De acuerdo con Cuco, 2013, la ciudad ha experimentado un intenso proceso de globalización en las dos últimas décadas, que ha estado especialmente influido por el ciclo especulativo urbanístico (1997-2007), unas políticas culturales que han querido hacer de la ciudad un referente cosmopolita y, paralelamente, unos procesos anexos de polarización social e intensa transformación de los paisajes urbanos. 
tercer lugar, se plantean una serie de interrogantes: ¿cuál es el viaje que ofrecen?, ¿cómo surge la idea?, ¿cómo se organiza y gestiona el viaje?, ¿qué tiene de distinto?, ¿cuál es su finalidad?, a partir de los cuales vemos las principales características de este tipo de viaje. Para, finalmente, realizar unas breves reflexiones a modo de conclusiones.

\section{TURISMOS Y ESPIRITUALIDADES}

En la segunda mitad del siglo XX, como consecuencia de la expansión del turismo de masas, de las rupturas históricas sucedidas a partir de los años setenta y del inicio de una segunda gran ola de patrimonialización cultural, la primera se había producido en coincidencia con la eclosión de la primera modernidad, se produjo una clara emergencia turística centrada en la cultura, en la medida en que, además, el patrimonio cultural iba adquiriendo una importante función económica como factor de desarrollo local (Hernández 2002). Ello fue acompañado de un creciente interés en este tipo de turismo por parte de las políticas culturales y turísticas de las instituciones. En este sentido, cabe recordar que en 1987, el Consejo de Europa instituyó un Programa de Itinerarios Culturales para potenciar el patrimonio cultural, el turismo cultural y la identidad histórico-cultural de los pueblos de Europa. Ello, unido a la aparición y perfeccionamiento de las nuevas tecnologías y medios de comunicación no ha cesado de potenciar este tipo de turismo.

La Organización Mundial del Turismo (OMT) define el turismo cultural "como la posibilidad que tienen las personas de internarse en la historia natural, el patrimonio humano y cultural, las artes y la filosofía, así como las instituciones de otros países y regiones". Una amplia definición que en realidad nos conecta con los distintos significados que se le otorgan al concepto de cultura y que nos ayudan a rastrear distintas posibilidades de desarrollo turístico cultural. Así, en un sentido antropológico, la cultura se entiende como el modo diferenciado de vida de un pueblo o de un grupo étnico, englobando en el mismo todas las manifestaciones y expresiones propias de dicho grupo. También utilizamos el término de cultura para referirnos al conocimiento y los saberes adquiridos. Y, en tercer lugar, como expresión artística y de ocio. Estas dos últimas acepciones tienen su origen en la concepción humanista de cultura que surge y se desarrolla a finales del siglo XVIII identificándose con creatividad estética e intelectual (Ariño 2000) ${ }^{3}$. De esta manera, el turista cultural engloba todas estas posibles formas de consumir cultura y que gráficamente podemos ver en la primera columna de la figura 1.

Podemos, además, señalar algunas características de este tipo de turismo, teniendo en cuenta que resulta esencial la práctica de un turismo activo cultural, así como la calidad y la oferta personalizada de los servicios requeridos. El turista cultural es alguien que generalmente, cuenta con un nivel cultural medio-alto, que realiza un mayor gasto económico en su viaje, manifiesta un interés por conectar con las gentes, los paisajes y las tradiciones del lugar, a los que suma el respeto por el medio ambiente y la cultura local (Hernández, 2005).

3 Las actividades creativas constituyen un campo autónomo, distinto de la vida cotidiana, separado de las esferas de la política y de la economía, que se rige por sus propios valores -el arte por el arte- y, por tanto, se halla por encima de los otros campos sobre los que establece su jurisdicción y crítica (Ariño, 2000:23). 
Figura 1

\section{LA POLISEMIA DE LA CULTURA Y SU RELACIÓN CON EL TURISMO DESDE UNA PERSPECTIVA OCCIDENTAL}

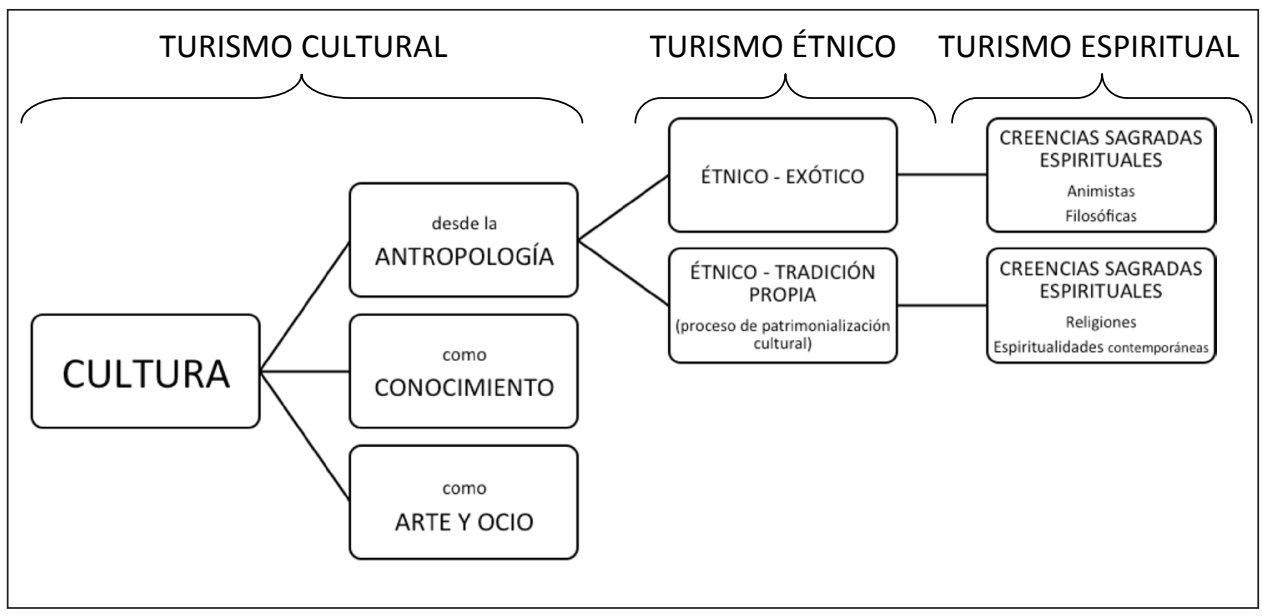

Fuente: Elaboración propia

Por otra parte, como puede apreciarse en la figura 1, desde la cultura en un sentido antropológico se deriva el turismo étnico. A este tipo de turismo la literatura especializada también lo llama etnoturismo ${ }^{4}$ e incluso, como turismo de las etnias. Como apunta Galinier y Fioravanti (2006) lo étnico puro, más nativista y menos sincrético, se ha vuelto uno de los instrumentos más flexibles de invención cultural. Éste turismo étnico contempla una doble vertiente ${ }^{5}$, puesto que se interesa por las lejanas culturas indígenas para el imaginario occidental ${ }^{6}$.Así, durante los viajes que se emprenden, uno se adentra en una realidad cultural diferente, se aprende a través del acto turístico a conocer y frecuentemente, a valorar elementos culturales relevantes (Amirou, 2000). Por otra parte, el turismo étnicoindaga en aquellos aspectos tradicionales que se han ido perdiendo en el contexto occidental y han entrado en un proceso de patrimonialización cultural. Lo podemos apreciar en la segunda columna de la figura mencionada.

Éste es el escenario donde cabe situar la emergencia del turismo espiritual como una deriva del turismo étnico, véase la tercera columna de la figura 1, y que no debe ser

4 Morales (2008) distingue entre etnoturismo y turismo indígena. El primero se refiere a las actividades que pueden realizar los turistas con los pueblos indígenas. El segundo a la construcción participativa de las etnias para ofrecer servicios turísticos, consensuados a través de encuentros, buscando interactuar de una manera crítica y responsable, solidaria con la naturaleza y con su identidad cultural.

5 Ciertamente hay autores que se refieren al turismo cultural como el relacionado con el patrimonio cultural occidental y al turismo étnico para referirse al relacionado con "otras" culturas.

6 Las categorías genéricas "Occidental" e "Indígena", construidas en la larga historia de contactos entre las Américas y a Europa representan los dos polos que delimitan un campo relacional donde se enmarcan la diferencias culturales y sociales que emergen en los contactos que se establecen a través del turismo y donde el occidental manifiesta una imagen idealizada del indígena. 
confundido con el turismo religioso. Si bien el turismo religioso puede ser considerado cómo la forma más antigua de turismo al combinarse conceptualmente con el fenómeno de la peregrinación ${ }^{7}$; aunque ciertamente, tanto el turismo espiritual como el turismo religioso pueden coincidir en la localización y en las formas de acceder y establecer contacto con lo sagrado, con lo trascendente, con la divinidad o con lo sobrenatural, pues las tradiciones religiosas pasan a ser vistas como exóticas o esotéricas. Así, los lugares religiosos se transforman en espacios multifuncionales, donde es posible convivir desarrollando un amplio abanico de actividades culturales, de ocio y de espiritualidad (Cànoves y Blanco, 2011). A estos espacios que pueden compartirse con el turismo religioso hay que añadir aquellos otros en los que se practican estas nuevas espiritualidades, unas veces en contacto con la naturaleza, otras en medios urbanos. Podemos pues distinguir un turismo espiritual de la mano de las creencias sagradas y espirituales de otras culturas a las que se visita in situ en viajes de largo recorrido, unas veces de carácter animista, otras desde sus antiguas filosofías. Y, por otra parte, un turismo espiritual que se realiza en el propio territorio, popularmente conocido como turismo de "retiro espiritual" (Albert, 2018).

En este artículo vamos a focalizarnos en el emergente turismo espiritual y en sus actuales desarrollos relacionados con los viajes de largo recorrido, aquellos que se realizan a las llamadas culturas indígenas y que han sido sometidas a un proceso de exotización. En este sentido, son muchos los destinos que se han erigido como un estandarte portando el sello de la espiritualidad. Estos lugares, en tan solo unas décadas, se han convertido en atractivos turísticos y se han transformados en lugares de peregrinación "neo pagana". Ello requiere también, atender las nuevas formas de practicar sentidos colectivos e incluso nuevos comunitarismos transterritoriales, mediante rituales de la religiosidad contemporánea (De la Torre 2008:54). Un ejemplo etnográfico de ello, pero podríamos citar muchos otros, sería el de la localidad de San Juan Chamula, en los Altos de Chiapas (México), lugar sagrado que ofrece la posibilidad de visitar un "auténtico santuario indígena", caracterizado por su espiritualidad y por los tratamientos terapéuticos y chamánicos que acercan a los visitantes a los orígenes místicos de la humanidad (Bayona, 2015:42). En lo que sigue, vamos a ver como se constituye y cuáles son las características de la creciente oferta de estos viajes espirituales que se articulan desde una ciudad, concretamente Valencia y que, en gran medida, podemos hacer extensivo a cualquier otra ciudad española e incluso europea.

7 Hay autores que mencionan la peregrinación como sinónimo del turismo religioso o como modalidad del mismo, otros estudiosos establecen comparaciones entre ambos términos. Victor Turner y Edith Turner sostienen que existen dos tipos de peregrinaciones: las que están relacionadas con lugares sagrados muy antiguos vinculados con los fundadores de una religión, como es el caso de Jerusalén o Roma para el cristianismo, la Meca por el Islam o Benarés para el hinduismo; y otras en las que es evidente un sincretismo, ya que están vinculadas a lugares donde antes existía un importante culto pagano, como es el caso por ejemplo de Glastonbury en Inglaterra o Chalma en México (Turner y Turner, 1978:14-16). 


\section{PROTAGONISTAS}

Aunque ciertamente podemos encontrar algunas agencias de viajes especializadas o con alguna sección específica que ofertan viajes espirituales, hoy por hoy siguen siendo escasas, teniendo en cuenta el volumen de personas que hacen este tipo de viajes. Lo que si nos abre un sinfín de opciones y destinos es una búsqueda por Internet donde se anuncian en numerosos blogs, páginas webs o videos en youtube, múltiples posibilidades. Tras estos blogs, o webs o videos se encuentran, principalmente, los centros/escuela holísticos, así como los espacios de encuentro del ambiente espiritual a los que nos hemos referido. En ocasiones, lo que nos encontramos son personas individuales de reconocido prestigio ( swamis $^{8}$, gurús, chamanes y maestros) que, de alguna manera también están vinculadas a estos nodos articuladores. Pues es a través de ellos que se organiza gran parte de la oferta de los viajes espirituales.

Así, los principales protagonistas de esta oferta de viajes espirituales la encabezan aquellos quienes gestionan y/o participan los espacios a los que nos hemos referido del ámbito espiritual. Cabe pues, que nos detengamos un momento en ellospuesto que, en muchos casos, han vivido en primera persona "su propio viaje". Así, lo relata uno de nuestros informantes, al que llamaremos Luis ${ }^{9}$, que dispone de unas instalaciones -varias construcciones en plena naturaleza- en la provincia de Castellón donde colaboran numerosos terapeutas y neochamanes ofreciendo una amplísima gama de actividades y consultas personales,

“...empecé a viajar también de otra manera, a viajar, así como, como experimentando un poco pues la vibración ¿no? Las cosas que te va, que te va trayendo la vibra, la vida de forma fortuita ¿no? Pues fui experimentando un montón de cosas. Y con el tiempo cuando ya tuve la oportunidad, reuní el dinero y pude, pues ya empecé a viajar a Perú..."

El viaje aparece como el inicio, como en el caso anterior, pero también como la culminación de su propia búsqueda espiritual o de realización personal. Cabe señalar que los destinos que han aparecido reiteradamente en nuestro trabajo de campo se refieren en el ámbito americano a México y Perú principalmente, también aparecen con cierta frecuencia Colombia y Ecuador. En Oriente, el destino estrella es la India y países cercanos como Nepal y Bután y en algún caso China. Estos buscadores espirituales, no sólo se acercan a una realidad cultural distinta, lo realmente destacable es la forma en que lo hacen ya que pretenden en todo momento distanciarse del turista común y prefieren autodenominarse como viajeros. Ruiz et al. (2011) en su trabajo en el santuario en el que se ha convertido San Cristóbal de las Casas (México), señalan que los turistas espirituales no llegan a esta ciudad con el propósito de ser meros espectadores de los rituales de sanación. Al contrario, sienten la necesidad de participar en ellos para que obren una transformación personal. Tratan, además, de aprender de la cultura a la que se acercan, practican en ella,

8 Se le llama Swami, significa literalmente, amo de sí mismo, pero también señor o dueño. También se utiliza como signo de respeto para dirigirse a un maestro espiritual.

9 Por supuesto se trata de un nombre ficticio, como en el resto de ejemplos mencionados. 
y en ocasiones, entablan una serie de relaciones personales qué, con el tiempo, en algunos casos, se convierten en profesionales. Ello les lleva a tener un contacto permanente puesto que, en muchos casos, han optado por una profesión relacionada con la espiritualidad. En nuestro trabajo de campo, hemos encontrado ejemplos al respecto. Así nos lo relata una informante, a la que nos referiremos como Mireia, que dirige un centro de ayurveda en la ciudad de Valencia,

“...me fui a India todo el verano y allí fue un gran salto también porque aprendí con un maestro médico. En ayurveda son los médicos quienes te enseñan, los terapeutas trabajan con los médicos casi siempre y te van enseñando las diferentes técnicas de masajes, de tratamientos, etcétera. Hice mucho yoga ahí, después... Mi formación siguió porque volví a India y fue en un hospital ayurvédico donde trabajé un mes que era muy duro y que no correspondía exactamente a mi filosofía y fui a 1200 kilómetros en el norte a encontrar a un médico que sí, que me gustó mucho y con quien estoy todavía colaborando, que viene dos veces al año a Valencia..."

Vemos la importancia que manifiestan en la realización de "su viaje" como un punto de inflexión iniciático y que han hecho de forma autodidacta. Se han ido, como ellos dicen, "a la aventura", sin una ruta o itinerario cerrado, sin un tiempo establecido, etc. En muchos casos, lo han hecho como "mochileros", sin saber con seguridad lo que estaban buscando pero que expresan, en sus propias palabras "con algo relacionado con la espiritualidad", "con encontrarse consigo mismo", "con conectar con la propia esencia". Así lo sintetiza uno de nuestros informantes: "...yo he sido mochilero, no se me ocurría otra forma de viajar para conocer de verdad lo que estaba buscando...".

Estos viajeros, con el tiempo se han establecido en sus propios centros/escuela ofreciendo sus servicios como terapeutas en la mayoría de los casos investigados. A través de ellos, se realiza esta oferta de viajes espirituales a la que vamos a referirnos en lo que sigue. A modo de una cata de un menú de degustación presentaremos la tipología de posibilidades que nos hemos encontrado en nuestro trabajo de campo y mostraremos como el viajero se adentra en una cultura distinta a la que el imaginario occidental se refiere como indígena. Pues resultan atractivas por su colorido y vistosidad, son ricas en sus creencias, son auténticas, tanto en su noción esencialista como experiencial ${ }^{10} \mathrm{y}$, se conserva ese ideal romántico de que se encuentran en simbiosis con la Tierra, plagadas de espiritualidad, de lugares mágicos, de espacios de poder, de centros energéticos, conservan pues, en el imaginario occidental una pureza y autenticidad de la que Occidente carece. Por ello, están siendo reconvertidas simbióticamente en una fuente de espiritualidad universal, que puede ser equiparable y por tanto combinable, con otras tradiciones culturales, de oriente y occidente (De la Torre, 2008:57). Así, lo refiere Luis,

10 Ambas son una proyección que los turistas hacen de sus creencias, expectativas, preferencias, imágenes estereotipadas y conciencia sobre los objetos turísticos, particularmente sobre los turísticos Otros (Wang 1999:355). 
“...pasé por todo lo que es el valle sagrado de los incas y otros lugares de, bueno pues de poder ¿no? De culturas ancestrales de los paracas, de los nazca, de otras culturas peruanas. Y también pues empecé a, a tener como una cierta sensibilidad, a sentir cosas en esos lugares de poder. En, en bueno, en antiguos centros ceremoniales..."

Ellos, después de haber vivido su experiencia, brindan la posibilidad de hacer un viaje "espiritual". Así, en un breve espacio de tiempo, sin tener que ocuparse de nada, el "turista" llega directamente al lugar adecuado para vivir su experiencia espiritual, para poder "conectar" consigo mismo ya sea a través del lugar, del grupo o del especialista.

\subsection{Su oferta}

La Escuela Tantien ${ }^{11}$, abre sus puertas en su forma actual en el año 2011, aunque cuenta con una dilatada experiencia. Está dedicada a la enseñanza y práctica del Taichi, Chikung y otras artes afines como Yoga, meditación, conciencia corporal, desarrollo personal, etc. Desde la escuela se ofrecen viajes a China desde hace más de una década. A pesar de que, como puntualiza su maestro y director, Félix,

"no me gustan los viajes organizados, sin embargo, estoy organizando un viaje, parece una contradicción, pero claro, lo hacemos de forma muy libre, para mí era un reto, y yo creo que lo hemos conseguido porque ofrecemos un viaje muy bonito y muy de verdad, conectamos con la esencia de China"

Se trata de un viaje ${ }^{12}$ guiado de la mano del maestro Wang Xiaojun junto con guías locales y del propio Félix. Diseñado para la inmersión en la cultura, costumbres y tradiciones chinas, especialmente con las filosofías tradicionales, el origen de las artes marciales, el taichí y el chikung. El viaje hace un recorrido por las ciudades de Pekín ${ }^{13}$, de Xian ${ }^{14}$, de Wudangshan donde se convive y se visitan diferentes templos y lugares emblemáti$\cos ^{15}$. Durante el viaje se práctica taichí y chikung con maestros acompañantes y se tiene contacto directo con el Instituto Chino de Investigación de Wushu y Medicina Tradicional China, que ofrecen charlas y explicaciones de dichas artes, así como de la cultura china en general. En este viaje se pretende un acercamiento a otros conocimientos y saberes ancestrales propios de la cultura china.

Otro ejemplo sería el de Mireia, terapeuta ayurveda que dispone de su propio centro, +Ayurveda, donde atiende en consulta privada y combina con otras actividades; también da clases de formación ayurvédica en otros centros de la ciudad. En el año 2010 organizó

11 Al frente de la misma se encuentran Anabel Esteve y Félix Castellanos, este último ha recibido el aprendizaje y reconocimiento de forma directa de un linaje de grandes maestros, concretamente de TaijiQuan estilo Chen de Pekín.

12 El precio del viaje es de unos $2.500 €$, variando ligeramente según tasas de aeropuerto.

13 La Plaza de Tiananmen, la Ciudad Prohibida, la Gran muralla, Tian Tan (Parque del Cielo).

14 El Museo de los Guerreros de Terracota y la Gran Mezquita.

15 Los templos de Despeñadero del Sur, Nube Púrpura, Pico Dorado y lugares como el Palacio del Príncipe y el Valle de los Monos. 
el primer grupo que viajó hasta la India con la finalidad de realizar un tratamiento integral durante tres semanas en una clínica ayurvédica de la India, en sus propias palabras "es una aventura personal y humana muy interesante". A este viaje, podríamos llamarlo terapéutico, puesto que el objetivo prioritario está relacionado con el tratamiento ayurvédico que se recibe. Sin embargo,

“... el ayurveda no contempla el equilibrio físico sin el mental, el espiritual... es muy importante tener la mente tranquila, hay gente que ha venido con depresiones, con mucha tristeza y se ha vuelto bien, en este sentido contemplamos la espiritualidad, con los hábitos del yoga, la meditación, es un todo..."

Otras veces, este tipo de viajes no se ofertan directamente desde un centro, sino que más bien, éste actúa como un nodo de divulgación y de información que los anuncia entre sus usuarios. Ello ocurre, especialmente, en establecimientos como las herboristerías, tiendas ecológicas y librerías especializadas. Aunque, lo que más bien destaca, es la oferta que se realiza desde personas estrechamente vinculadas a centros y, muy especialmente, a las escuelas de Yoga. Yolanda es una de las alumnas en uno de estas escuelas donde está realizando la formación de Kundalini Yoga

“...me inicio en estos viajes porque me apasiona Marruecos, yo conocía Marruecos por el tema de la montaña, hago montaña hace más de 20 años, es un país que encanta, me apasiona... [...] ...no acabamos de sacarle la esencia al lugar, al sitio, a esas playas tan bonitas, ni a llevar una convivencia con los bereberes, tan interesante, no podemos llevarla porque ellos trabajan demasiado... [...] ...en ese momento empiezo a conocer el mundo del yoga y me doy cuenta de que esto es un escenario totalmente incomparable a todos los lugares donde hacemos yoga. Entonces se me ocurre eso, pues voy a montar un viajecito..."

Aurora, sería otro caso, también profesora de yoga y vinculada a una escuela donde imparte clases; en realidad busca dedicarse a la organización de viajes de forma más profesional y poder combinar ambas actividades. Se confiesa una enamorada de la India y deseosa de compartir sus vivencias personales en este país.

“...bueno desde el 2010 que fue la primera vez que fui a India, luego cada año volví a India y cada vez era por más tiempo. O sea, mitad del año allá, mitad del año acá y siempre tuve la idea de hacer un tour, o de llevar gente a conocer porque a mí me, me gustó tanto y, y para mí es como mi casa ¿no? Y me siento... No sé, siento que he pasado tantos cambios y tantas crisis internas en India, como que India te sacude un poco ¿no? Como que es una energía muy fuerte la que se siente ahí y los extremos que se viven también y repercute mucho en la gente... [...]... es difícil de explicar, pero ¿Qué pasa en India? No sé. Como que hacía rato que quería organizar algo para llevar gente a que puedan experimentar esto que yo ya experimenté..." 
Otras veces, el que lanza la oferta del viaje es un personaje de reconocido prestigio en el ámbito espiritual, ya sea un gurú, un maestro o un chamán. Sería el caso del SwuamiPuroit ${ }^{16}$, afincado en Granada, imparte cursos y talleres del antiguo conocimiento védico por toda la geografía española, y, hoy en día, está considerado uno de los grandes expertos de Yoga y Meditación. Cada año ofrece a sus estudiantes, la oportunidad de compartir un viaje a la India y visitar lugares sagrados, concretamente, Tiruvannamalai (cerca de Chennai al sur de India) ${ }^{17} \mathbf{y}$ el Ashramde Sri RamanaMaharshi, lugar donde se realizan los retirosespirituales, se practica yoga y se reciben enseñanzas. Durante el viaje, también se visitan los templos de la zona, aunque no pretende ser un viaje turístico sino un peregrinaje pensado para aquellas personas que quieren experimentar, de primera mano, la esencia de la India y ahondar en su desarrollo personal. Dicho viaje se realiza durante el mes de Agosto en dos opciones, la corta de nueve días y la larga de dieciocho días ${ }^{18}$.

En otras ocasiones, estos personajes de reconocido prestigio combinan la gestión de sus actividades, consultas, talleres, seminarios, etc. así como de los viajes que realizan con centros o personas vinculadas a ellos. Sería el caso de Gerardo Pizarro, poderoso chamán

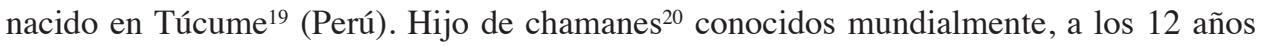
se adentró en la Amazonía peruana y permaneció entre los pueblos indígenas donde fue iniciado, aprendió y adquirió conocimientos acerca de las plantas, y hierbas curativas, especialmente de la hierba del dragón; así como, los secretos de sus rituales ${ }^{21}$. Durante la década de los años ochenta empieza a trabajar en Europa donde finalmente se establece, desde donde viaja y trabaja ${ }^{22}$. Gerardo nunca perdió el contacto con los pueblos indígenas donde se inició y desde hace décadas, cada dos años organiza un viaje a Perú con grupos de 25-30 personas para que emprendan lo que él llama la "aventura chamánica" y que consiste en un viaje de 21 días que recorre Perú de arriba a abajo ${ }^{23}$. Esta aventura chamánica, en sus propias palabras,

“... incluye un trabajo que consiste en armonizar los tres mundos o los tres cuerpos de expresión que se combina con los atractivos turísticos y mágicos del lugar que se visita. Se trata de un viaje "incomodo" en los que se llega a "lugares de poder", de mucha fuerza de la naturaleza donde se han venido forjando los chamanes peruanos

16 Nació en la India, además de su formación científica en matemáticas, también estudió la ciencia védica y practicado la Meditación, así como todas las ramas del Yoga con grandes maestros de todas las tradiciones durante más de 30 años.

17 Tiruvannamalai es uno de los lugares más venerados en India. Antiguamente el término "Annamalai" significaba una montaña inaccesible y la palabra "Thiru” se añadía para indicar grandeza, así se juntaron las dos palabras para llegar al nombre de Tiruvannamalai. Las primeras referencias a Tiruvannamalai datan del siglo IX.

18 La corta de 9 días cuesta $675 €$ y la larga de 18 días, $1450 €$. No incluye vuelos internacionales entre España y la India, visados ni seguro de viaje

19 Departamento de Lambayeque, provincia de Chiclayo (Perú).

20 Los dos nacidos en la costa norte del Perú en el seno de familias de chamanes y curanderos.

21 A los 14 años, ya iniciado en los secretos de las plantas sagradas, regresa con su madre, Andalia Carranza y completa su formación en el camino del chamanismo y la sanación.

22 En el centro de su trabajo se encuentran la Mesa Ritual Peruana, consultas, baños de florecimiento, masajes chamánicos, la limpia con el huevo, etc.

23 Desde la capital, Lima partirán hacia Chiclayo, Túcume, Huamcabamba, LasHuarinjas, Laguna Negra, Cuzco llegando hasta el Machu Picchu. 
desde tiempos inmemoriales, puesto que ellos viven y trabajan en contacto con los elementos, en zonas inhóspitas y muy alejadas de los centros urbanos..."

Durante los días 4 y 7 de febrero de 2016, Gerardo Pizarro estuvo en Valencia donde atendió en consulta individual, con baños de florecimiento y masajes chamánicos, y de forma colectiva en una mesa sanadora a la que acudieron unas 50 personas, dando charlas en ambos lugares, sobre el chamanismo y sobre el viaje iniciático ante un público entregado y fuertemente interesado en este viaje. Volvió en junio de 2016 y en enero de 2017, realizando nuevamente mesas sanadoras colectivas y consultas individuales; todo ello a cargo de una facilitadora de constelaciones familiares que durante años ha regentado un centro en Valencia y que desde el año 2014 trabaja de forma independiente e itinerante en salas polivalentes en la Comunidad Valenciana.

\section{CARACTERISTICAS DEL VIAJE ESPIRITUAL}

Hemos visto hasta aquí la configuración de un circuito alternativo para realizar viajes espirituales, al margen de las tradicionales agencias de viaje si se quiere viajar en grupo, o de los viajes como "mochileros" si se hace en solitario y que se articulan, fundamentalmente, alrededor de los centros/escuela holísticos. La actual polifonía entre espiritualidad y terapias abre nuevos puentes entre grupos locales en búsqueda de recursos y visibilidad internacional y un público occidental cultivado, en búsqueda de nuevos valores que deben concretizarse en experiencias sensoriales exóticas, a la vez individuales y compartidas (Losonczy y Mesturini, 2010:180). Nos hemos situado en el lado de la oferta mostrando, desde dónde y quiénes organizan estos viajes espirituales, lo que nos abre interrogantes respecto a las características propias del viaje; aunque son muchas las preguntas que se revelan, vamos a detenernos en las siguientes: ¿cómo fueron concebidos?, ¿cuál es la principal motivación?, ¿cómo realizan su organización? y ¿cuál es su finalidad?

En el caso deGerardo Pizarro, éste tiene el compromiso de visitar periódicamente a los pueblos indígenas que lo acogieron y que le dieron parte de sus enseñanzas como chamán. De esta forma, brinda la oportunidad de dar a conocer culturas ancestrales a los visitantes. Sin embargo, tal como apunta Auge (1998) los grupos indígenas van transformando su propia herencia y costumbre religiosa en espectáculo para los turistas, ejemplo de ello son los rituales chamánicos, los temascales, los ritos con plantas sagradas alucinógenas y las limpias. Muchas de las nuevas recreaciones rituales, están siendo readaptadas por los propios nativos. Tal como apunta De la Torre, 2008, hoy en día, huicholes, incas, mayas, otomies; chamanes, babalaos y marakanes y curanderos están reconfigurando sus tradiciones, en la medida en que reincorporan como "auténtico" lo que ellos mismos recientemente diseñaron para que el turista extranjero consumiera. (De la Torre, 2008:59). La "occidentalización" de la demanda suscita paradójicamente una estandarización creciente de la acción ritual a través de la yuxtaposición casi obligatoria de las secuencias ritualizadas (Losonczy y Mesturini, 2010:180). Parece pues, que la reinvención de rituales ancestrales no solo es implementada por los neo indígenas, sino también por los miembros tradicionales de los grupos étnicos, que para vender su cultura como turismo espiritual están "ficcionando" sus rituales, adaptándolos a la mirada imperial exotizante de los 
extranjeros. Los ritos nativistas son hoy revalorados como místicos, naturales, ancestrales, mágicos o espirituales.

La llegada de turistas sirve de ayuda a la conservación de dicha cultura, así lo especifica Gerardo, “...el grupo siempre compra cositas, collares, pulseras, piedras, también objetos poderosos...". Como ilustran estas líneas y, de acuerdo con De la Torre (2008) la nueva red de mercado esotérico ofrece artículos con poderes mágicos o terapéuticos, que provienen de distintas tradiciones religiosas: budistas, hinduistas, esotéricas, brujería, magia blanca, espiritismo, catolicismo popular, cosmovisiones prehispánicas, mancias celtas o africanas, etc. Una cuestión fundamental, que queremos destacar es que el nuevo esoterismo, ha dejado de ser oculto, y se ha convertido en un exotismo de la mano de la new age y de sus desarrollos posteriores. No estamos de acuerdo, sin embargo, en que se trate de un patrón de consumo tendiente a encontrar soluciones mágicas a los problemas cotidianos: de salud, de amor, de trabajo, de dinero sin ofrecer un nuevo estilo de vivir como apunta la autora, puesto que el viaje ya se configura y se experimenta de una forma alternativa.

Para SwamiPuroit, este viaje se concibe desde otra óptica, pues él está dedicado a la divulgación de las enseñanzas orientales por toda España, haciéndolas asequibles y practicables a las mentes occidentales.

“...yo he venido a Occidente a compartir mi visión interna de cómo vivir en libertad y creatividad. Hoy en día se está viviendo una vida desequilibrada, en conflicto y descontento con nosotros mismos. Yo enseño a desarrollar todo el potencial del ser humano para alcanzar una completa expresión de uno mismo. El desarrollo armonioso del corazón y la mente es un requisito para vivir una vida grandiosa..."

Desde la idea de "yo enseño cómo vivir la vida de manera auto-suficiente. Cómo vivir con dignidad y poder, ahora y para siempre, ayudando a que cada uno descubra su ser esencial y lo desarrolle, aceptándolo..." se concibe también la idea de viajar a la India como una actividad más que posibilite este descubrimiento de sí mismo.

En el caso de Félix, como él mismo señala, "mi motivación inicial para ir a China fue la de formarme, yo fui para recibir enseñanzas de una profesora china". Sin embargo, después del aprendizaje y de la experiencia vivida, Félix quería compartir su viaje y la forma de hacerlo fue en compañía de su profesor en China, "al coordinarme con mi profesor me sentí seguro, porque claro, toda la parte de china se organiza desde allí por parte del profesor Wang" y de esta forma, además, "organizamos tanto los viajes como los cursos aquí, porque él viene todos los años aquí a Valencia y da cursos en la escuela". Así fue como empezó a proponerlo entre sus alumnos, amigos y conocidos, de forma que, rápidamente se puso en marcha la iniciativa.

“...La mitad de la gente son alumnos o ex alumnos, o se han enterado por internet, aunque no hacemos publicidad ni nada, amigos o conocidos de alumnos..."

Otro de los interrogantes que nos hemos formulado y que nos interesa destacar especialmente, es la motivación prioritaria que se manifiesta a la hora de organizar estos viajes. 
Puesto que, en todos los casos, expresan su deseo de compartir, su alegría ante los buenos resultados, la felicidad del grupo, etc. remarcando que no es la compensación económica, si la hay, el motivo fundamental teniendo en cuenta la dedicación y el considerable esfuerzo que implica. Veamos que nos dicen al respecto varios de nuestros informantes,

“...realizar este viaje forma parte del camino que llevo, del compromiso que tengo con mis clientes, con mis alumnos, también amigos, conocidos... no es una cuestión económica, en ese sentido podría no hacerlo porque no es la finalidad..." DMA12

“...Esto yo no lo hago para sacar dinero ni nada de eso, esto yo lo hago para poder hacer ese tipo de viaje, con un grupo de gente puedo organizar una caravana, porque ya te digo, yo sola, o con mi hija no me organizan una caravana..." DSR36

“...no es un negocio, aunque tenga su compensación, no es tampoco un trabajo, sino que es algo que él quiere hacer, que yo quiero hacer, por supuesto tenemos una compensación económica, pero descubre los lugares, la gente, su filosofía, su forma de vida, claro, el taichí también, pero como una parte más, un curso de taichí lo puedes hacer aquí, no hace falta hacer el viaje para eso..." HCT39

Los casos estudiados muestran que es precisamente esa solidaridad lo que les permite seguir realizando ese viaje de forma periódica. Solidaridad que expresan con dos palabras: compartir y mostrar. Estas se repiten en el discurso analizado con frases como "compartir la esencia del lugar". De esta forma se hace extensiva la experiencia y puede llegar a aquellos interesados en vivir esta experiencia espiritual.Para ello se hace necesario poder encontrarse con personas afines, en las que se reconocen unos a otros, personas que de alguna forma están buscando lo mismo y así, poder seguir aprendiendo, "creciendo". Manifiestan como, "el conocerse la gente, es muy bonito, hay una conexión muy íntima y muy armoniosa, se han hecho hasta parejas". Se presenta pues, una tendencia hacia la "tribalización" creciente de los comportamientos turísticos, es decir, aparecen comportamientos compartidos por diferentes sujetos (Maffesoli, 1992; Hiernaux, 2000). Al debilitarse la identificación de los grupos tradicionales, como la familia, el sindicato o el partido político, aparecen demandas vinculadas a las nuevas identificaciones entre los individuos, aunque sean identificaciones efímeras, y que resultan de intereses compartidos. Estos fenómenos de "tribalización" son importantes para el desarrollo del turismo, tienen implicaciones directas en él. Los grupos que el turismo atiende no son simplemente colecciones de individuos que se someten pasivamente a un mismo producto turístico, sino grupos de interés, que demandan productos y actitudes especializadas de atención hacia sus objetivos compartidos. Personas entre las que se acaban estableciendo fuertes vínculos personales y que en alguno de los ejemplos mostrados parten de un ideal cooperativo para hacer las cosas como se observa en la siguiente cita textual,

“...Claro, gente con las mismas inquietudes, cuanta más gente viene más económico nos sale... yo a lo mejor si tengo suerte, y viene suficiente gente yo no 
pago mi plaza, a cambio de organizarlo todo, de las clases de yoga y de estar al cuidado del grupo, porque claro, durante el viaje te puedes encontrar con muchos marrones..." DSR36

Viajar siempre hace que te alejes de la rutina diaria y que "desconectes" de las obligaciones del día a día. Un viaje de estas características, implica, además, compartir experiencias muy personales, lo que desarrolla un sentido de hermandad, de amistad, incluso de comunidad muy poderoso, "también es compartir, compartimos mucho, el grupo genera buenas ondas". La communitas $^{24}$, en el sentido que la expresa Turner (1988) como la perspectiva ideal de una cultura, representada por los actores como una condición atemporal, un eterno ahora, como un "momento dentro y fuera del tiempo" (Turner, 2007:522), aparece en la experiencia que se manifiesta y en la intención que se le otorga al viaje espiritual.

La organización del viaje implica una gran tarea de gestión y de coordinación, así como un gran conocimiento del lugar que se visita. Por otra parte, este viaje ofrece una serie de servicios especiales como son la sabiduría del maestro, gurú o profesor que les acompaña, así como las prácticas de meditación, yoga o taichí, según el caso. Comporta pues, la práctica de actividades de autoconocimiento o de crecimiento personal pero también de tratamientos terapéuticos que le ayuden y que le orienten en su búsqueda espiritual y de bienestar, pues de lo que se trata es de conocer y de aprender a través de la propia experiencia. En ninguno de los casos estudiados, el objetivo prioritario del viaje es la formación en esta materia. Lo que, si cabe señalar, es que estas actividades no se conciben como un servicio que se presta, sino como una actividad que se comparte y en la que se profundiza durante el viaje. Ciertamente, en algunos casos lo que se ofrece es un tratamiento relacionado con la salud, el bienestar y el crecimiento personal que se manifiesta, por ejemplo,

“... lo que estamos haciendo se llama pantzha-karma, que quiere decir las cinco limpiezas, es una cura integral, que incluye el tratamiento ayurvédico, masajes a cuatro manos, yoga, meditación, para sanar el cuerpo y la mente..." DMA12

Cabe subrayar la relación de amistad y de afinidad que se comparte con el grupo que viaja, en lo que se hace y en cómo se hace. Así,

“...con el tiempo las personas que forman parte del equipo, somos 5 o 6 personas, somos como un grupo de amigos, con un espíritu común, conectamos, buscamos lo mismo, hasta el punto que el año pasado hasta el conductor del autobús nos dijo que quería volver a venir con nosotros y así cada año..."HCT39

Generalmente se realizan una serie de reuniones periódicas con el grupo que va a emprender el viaje a través de las cuales se van conociendo y entrando en la cultura (char-

24 La perspectiva ideal de una cultura, un enfoque edénico, paradisíaco, utópico o milenario, para cuya consecución se debería dirigir la acción religiosa o política, personal o colectiva. 
las sobre costumbres, palabras y expresiones usuales, preparación del equipaje, formalismos, sugerencias prácticas, etc.). Estas reuniones previas, además propician la oportunidad de conocernos y generar un clima de armonía que, sin lugar a dudas, ayudan a generar unas buenas relaciones y camaradería durante el viaje y después del viaje. Resulta destacable, observar cómo se trata de viajes que no se publicitan, más que en el blog, o en la propia web del centro, como una actividad más ${ }^{25}$. Por su parte, los grupos de WhatsApp se revelan como una poderosa herramienta de difusión, "solo lo digo a mis contactos (refiriéndose al WhatsApp) y estos parece que se lo dicen a los suyos y de esa manera formamos el grupo para viajar" nos dice uno de nuestros informantes. Es pues, el boca a boca ya sea en un sentido literal o través de las redes sociales (seguidores de facebook, principalmente), lo que hace que cada año se vallan conformando los grupos y se realicen los viajes, "el boca a boca, la gente esta tan contenta que siempre hay lista de espera".

¿Con que finalidad organizan estos viajes? Félix se confiesa un gran amante de la cultura china, de sus costumbres y de su arte, también un estudioso y seguidor de la filosofía taoísta. De esta forma sigue el camino de la tradición oriental que combina con los conocimientos occidentales. En sus propias palabras "yo quería hacer algo un poco más espiritual y mostrar también la cultura china, sus costumbres, yo soy un enamorado de China". De una u otra forma todos los informantes expresan su deseo y su voluntad de penetrar en la cultura a la que viajan, se trata de poder adentrarse un poquito en la realidad del lugar. En este sentido, de acuerdo con Amirou (2000) cabe señalar la confrontación de modos de vida a partir del viaje, el aprendizaje de nuevas costumbres, por ejemplo, han sido factores decisivos en el desarrollo del turismo y lo seguirán siendo en el futuro, inclusive de un modo mucho más intenso. Entonces, habrá que considerar que el turista, no sólo busca información, también lleva consigo un interés tácito en construir conocimiento que le permita valorar su propia vida, o que le sirva de referencia para sus experiencias personales fuera de la esfera del viaje. El conocimiento como producto turístico se ha vuelto así esencial.

“...estas en India con terapeutas indios, comes como los indios, vives en un pequeño pueblo indio, en realidad con este viaje que no es turístico, conoces mucho mejor la India que con cualquier viaje que hagas en grupo o autobús, lo que sea, esta es otra forma de acercarse al país, claramente a nivel físico y de salud es maravilloso..." DMA12

Swuami Puroit, vincula la espiritualidad a la salud y al bienestar. Tal como anuncia en su página web "las prácticas de Yoga, Meditación y mantras que se proponen, no solo ayudan a mejorarlasalud física, sino que también desarrollan la mente y las emociones. La auto-sanación se consigue a través del mismo Ser. La paz interior previene la enfermedad. Siguiendo los pasos que enseña el Yoga, se consigue que la mente este en calma para alcanzar la paz interior. Tener paz interior significa tener capacidad de sanarse a uno mismo. Los que no tienen paz interior no pueden disfrutar de la vida. La tensión, la ansiedad, los miedos, la angustia vital terminan por enfermar el cuerpo. La ignorancia sobre sí mismo es la verdadera causante de la infelicidad en el ser humano".

25 En uno de los casos presentados se publicita en una revista especializada, concretamente, YoguiOla. 
En otros casos, lo que señalan como fundamental es el contacto con los elementos de la naturaleza y la posibilidad de manejarlos de alguna manera, cosa que para nosotros ya no es posible; ello te permite una mayor fusión con el lugar y contigo mismo.

“...el conectar con los elementos, que aquí ya no tenemos, aquí vamos siempre con zapatos, el fuego aquí lo ves en alguna barbacoa con carbón, allí tenemos una fogata de leña, el cocinero te hace el pan en un horno, hecho con la arcilla de la playa, en 10 minutos te organiza el horno y te hace el pan, el poderte bañar, dormir a orillas del mar, aquí eso ya no lo podemos hacer... [...] ...ver el cielo, las estrellas, no hay contaminación lumínica, no hay ruido, es maravilloso..." DSR36

En definitiva, aunque un viaje como éste ofrece muchas cosas, lo que señalan como fundamental es la búsqueda de sí mismo, el bienestar personal, del crecimiento interior, etc. ya sea a través de la conexión contigo mismo, con el entorno, ya sea a través de la práctica que realizas, yoga, meditación, etc. o de la sesión que se te ofrece, limpia chamánica, tratamiento terapéutico, etc., "la gente busca aventura y busca estar en un entorno en el que conecte con su ser”. A veces, incluso van más allá, puesto que en ocasiones se produce un cambio personal,

“... este viaje es un descubrimiento de lo que es bueno para ti, de lo que tú necesitas..." [...] “... es como que te cambia el chip, para algunos, no digo que para todos, pero para algunos es espectacular el cambio que se produce en ellos... "DMA12

Podemos pues, concluir que se trata de viajes que configuran un circuito alternativo al margen de las tradicionales agencias de viajes y que como hemos visto, comporta una serie de características propias.

\section{A MODO DE CONCLUSIONES}

Desde mediados del siglo pasado hemos asistido a una ampliación de las posibilidades turísticas de forma considerable; han aparecido nuevos tipos o han diversificado su oferta: histórico, cultural, ambiental, étnico, espiritual, etc., ampliando así su campo de acción. En este artículo, hemos querido reflexionar sobre un nuevo tipo de turismo que se está desarrollando en línea con la circulación de personas que recorren las redes espirituales en búsqueda de nuevas experiencias de lo sagrado y de la vivencia espiritual. Estos flujos, cada vez más numerosos pertenecen a un tipo de turismo cultural y étnico que oferta las tradiciones filosóficas y religiosas como exóticas o esotéricas y que aquí hemos llamado turismo espiritual distinguiéndolo del turismo religioso tradicional (cristiano fundamentalmente) si bien en algunos casos puede coincidir en el emplazamiento o lugar de destino.

Nos hemos situado en el lado de la oferta, es decir, en aquellos que organizan este tipo de viajes, los centros alternativos, personas vinculadas a ellos o personajes de reconocido prestigio (swamis, gurús, chamanes, etc.) en el ámbito espiritual. Todos ellos configuran un circuito alternativo al margen de las tradicionales agencias de viaje y de su interés 
lucrativo. Así, hemos mostrado algunas posibilidades que se ofrece desde una ciudad como Valencia, tratando de responder a los interrogantes que se nos revelan respecto a las propias características del viaje.

Estos viajes son concebidos desde el compromiso, ya sea éste con un pueblo indígena en particular, con una enseñanza concreta o con aquello que se ha experimentado y aprendido. Ellos se ofrecen a un viajero que busca nuevas experiencias, que viaja por el mundo para descubrir antiguos secretos de los pueblos indígenas, para vivir nuevas experiencias místicas, para asistir a un ashram o a un monasterio budista, etc. La principal motivación que manifiestan para hacerlo es la solidaridad, en cierta forma, compartir este viaje es lo que les permite seguir realizándolo de forma periódica. Y ello se expresa en dos formas, compartir y mostrar a los demás, a aquellos que se identifican como buscadores espirituales, lo que configura nichos especializados, que responden a las demandas de las nuevas tribus de la posmodernidad.

Por otra parte, la organización del viaje implica una relación de amistad y de afinidad en lo que se hace y en cómo se hace. Ello hace que se realicen una serie de reuniones periódicas con el grupo que va a emprender el viaje a través de las cuales se van conociendo y conociendo también la cultura la cual va a visitarse. Por otra parte, se trata de viajes que prácticamente no se publicitan, sino que es el boca a boca el que hace que cada año se vallan conformando los grupos.

En definitiva, aunque un viaje como éste ofrece muchas cosas, lo que señalan como fundamental es la búsqueda de sí mismo, el bienestar personal, del crecimiento interior, etc. ya sea a través de la conexión contigo mismo, con el entorno, ya sea a través de la práctica que realizas, yoga, meditación, etc. o de la sesión que se te ofrece, limpia chamánica, tratamiento terapéutico, etc. se trata de "conectar con tu propia esencia" y si ello se consigue puede significar un cambio personal trascendente.

\section{BIBLIOGRAFÍA}

ALBERT RODRIGO, M. (2018): Turismo espiritual. Del viaje interior a viajar por el interior del país,en Rubio, A. y Sanagustín, V. (Dirs.) Turismo Religioso. El camino europeo del Santo Grial y otras rutas culturales para el desarrollo. Madrid, Delta Publicaciones, pp. 73-82.

ALBERT RODRIGO, M. y HERNÁNDEZ MARTÍ, G.M. (2014a):“Lo Sagrado y la Memoria: Hacia una Teoría Sociológica del al Religión”,Revista de Observaciones Filosóficas, $\mathrm{n}^{\circ} 17$.

ALBERT RODRIGO, M. y HERNÁNDEZ MARTÍ, G.M. (2014b): “Los movimientos psico-espirituales en la modernidad globalizada. Una mirada desde la ciudad de Valencia”, AIBR. Revista de Antropología Iberoamericana,vol. 9 (3), pp. 273-296.

AMIROU, R. (2000): Imaginaire du tourismeculturel. París, Presses Universitarire de France.

ARIÑO, A. (2000): Sociología de la cultura. La constitución simbólica de la sociedad. Barcelona, Ariel.

AUGÉ, M. (1998): El viaje imposible. El turismo y sus imágene. Barcelona, Gedisa. 
BAYONA ESCAT, E. (2015): "Rituales indígenas y otras escenificaciones turísticas en los Altos de Chiapas", Nueva Antropología, vol. 38 (82), pp. 31-50.

CÀNOVES VALIENTE, G. y BLANCO ROMERO, A. (2011): "Turismo religioso en España: ¿La gallina de los huevos de oro?Un vieja tradición, versus un turismo emergente", Cuadernos de Turismo, $\mathrm{n}^{\circ}$ 27, pp. 115-131.

CUCÓ, J. (2013): La ciudad pervertida. Barcelona, Anthropos.

CHAMPION, F. (1995): "Persona religiosa fluctuante, eclecticismo y sincretismos", en El hecho religioso. Enciclopedia de las grandes religiones. Madrid, Alianza Editorial, pp. 705-737.

DAVIE, G. (2011): Sociología de la Religión. Madrid, Akal.

DE LA TORRE, R. (2008): "La imagen, el cuerpo y las mercancías en los procesos de translocalización religiosa en la era global”, Ciencias Sociales y Religión, ${ }^{\circ} 10, \mathrm{pp}$. 49-72.

DÍAZ-SALAZAR, R. (1994): La religión vacía. Un análisis de la transición religiosa en Occidente. Formas modernas de religión. Madrid, Alianza Editorial.

GALINIER, J. y MOLINIERÉ, A. (2006): Néo-Indiens (Les): Une religion du IIIemillénaire. Odile Jacob.

HERNÁNDEZ MARTÍ, G.M. (2002): La modernitatglobalitzada. Anàlisi de l'entorn social. Valencia, Tirant lo Blanch.

HERNÁNDEZ MARTÍ, G. M. (2005): La difusión del patrimonio cultural y el turismo. La memoria construida. Patrimonio cultural y modernidad.Valencia, Tirant lo Blanch.

HERVIEU-LÉGER, D. (2005): La religión, hilo de memoria. Barcelona, Herder.

HIERNAUX, D. (2000): "La fuerza de lo efímero: apuntes sobre la construcción de la vida cotidiana en el turismo", en La vida cotidiana y su espacio temporalidad.México, Anthropos y El Colegio Mexiquense, pp. 95-122.

LAFAN, M.F. (1994): "Identité, Mémoire, Patrimonie et “Toursitificación” de nos sociétes". Sociétés, n46, 433-439.

LENOIR, F. (2005): La metamorfosis de Dios. La nueva espiritualidad occidental. Madrid, Alianza Editorial.

LOSONCZY, A.M. y MESTURINI, S. (2010): "La selva viajera Rutas del chamanismo ayahuasquero entre Europa y América”. Religiao e Sociedade, vol. 30 (2), pp. 164-183.

MAFFESOLI, M. (1992): La transfiguration du politique. La tribalisation du monde. París, Le Livre de Poche.

MARDONES, J.M. (1999): "Nueva Espiritualidad. Sociedad Moderna y cristianismo", Cuadernos de Fe y Cultura, vol. 11. Universidad Iberoamericana.

MORALES GONZÁLEZ, M. (2008): “Etnoturismo o turismo indígena?”, Teoría y Praxis, $\mathrm{n}^{\mathrm{o}}$ 5, pp. 123-136.

RITZER, G. (2000): El encanto de un mundo desencantado. Barcelona, Ariel.

RUIZ, M.A. et al. (2011): "Consumidores alternativos: turismo étnico y espiritual new age en los procesos de reinvención del imaginario urbano en San Cristóbal de las Casas. México”,Pasos. Revista de Turismo y Patrimonio Cultural, vol.5, pp. 289-305.

SHIMAZONO, S. (1999): "New Age Movement" or "New Spirituality Movements and Culture"?", Social Compass, vol. 46 (2), pp. 121-134. 
TURNER, V.W. y GARCÍA RÍOS, B. (1988): El proceso ritual. Estructura y antiestructura. Madrid, Taurus.

TURNER, V.W. (2007): Pasos, márgenes y pobreza: símbolos religiosos de la communitas. Lecturas Antropología. Madrid, McGraw Hill.

TURNER, V. yTURNER, E. (1978): Image and Pilgrimage in Christian Culture: Anthropological Perspectives. Columbia University Pres.

WANG, N. (1999): "Rethinking Authenticity in tourism Experience". Annals of Tourism Research, vol. 26 (2), pp. 349-370. 